\title{
Adolescents Discussing Sexual Behaviors With Key Influencing
} Audiences

\author{
Judith Nalukwago ${ }^{1,2,3}$, Rik Crutzen ${ }^{1}$, Bart van den Borne ${ }^{1}$, Paul M. Bukuluki ${ }^{3}$, Leonard Bufumbo ${ }^{2}$, Richard \\ Batamwita $^{2}$, Amos Zikusooka $^{2}$, Rachel Lenzi ${ }^{2}$, Gretchen Thompson ${ }^{2}$ \& Jane Alaii ${ }^{4}$ \\ ${ }^{1}$ Department of Health Promotion, CAPHRI Care and Public Health Research Institute, Faculty of Health, \\ Medicine and Life Science, Maastricht University, The Netherlands \\ ${ }^{2}$ FHI 360 (Family Health International), USAID/Communication for Healthy Communities Project, Uganda and \\ USA \\ ${ }^{3}$ Department of Social Work and Social Administration, School of Social Sciences, Makerere University, Uganda \\ ${ }^{4}$ Context Factor Solutions, P.O Box 27598-00100, Nairobi, Kenya \\ Correspondence: Judith Nalukwago, Department of Health Promotion, Maastricht University, The Netherlands. \\ Tel: 31-683-963-732. E-mail: j.nalukwago@maastrichtuniversity.nl
}

Received: June 10, 2018 Accepted: July 10, 2018 Online Published: July 25, 2018

doi:10.5539/gjhs.v10n8p91 URL: https://oi.org/10.5539/gjhs.v10n8p91

\begin{abstract}
There is an increasing concern on early initiation of sexual activity among adolescents, increasing sexually transmitted infections, and teenage pregnancy in Uganda. Adolescents perceptions of these sexual behaviors might be the result of discussing sexual and reproductive health issues with key influencing audiences. This study qualitatively explored the effect of sexuality discussions with key influencing audiences by means of in-depth interviews and focus group discussions with adolescents $(\mathrm{N}=83)$. Findings indicate that adolescence stage comes with changes of intense sexual desires, often presumed difficult to control thus leading adolescents to engage in sexual activities. Adolescents indicated that they were aware of the sexual behaviors such as condom use, contraception use, and multiple concurrent partnerships, but intertwined with persistent myths and misconceptions Although discussing sexuality issues with someone was found to be instrumental, adolescent highlighted challenges that hinder discussion with key influencers. Challenges include, parents lack of time to talk to their children; some religious affiliations perceived to discourage use of contraception; limited skills of community health workers to address adolescent information needs; meetings held in groups not followed up with age-focused or one-on-one discussions; negative health workers' attitudes and use of technical language; and peer pressure. These findings suggest the need to provide adequate and updated information to clear any misconceptions and strengthening of key influencers' communication skills to gain confidence in addressing adolescent sexual and reproductive health needs.
\end{abstract}

Keywords: adolescents, condom use, contraception, multiple concurrent partnerships, key influencers

\section{List of Abbreviations}

SRH: Sexual and Reproductive Health; IDI: In-depth Interviews; FGDs: Focus Group Discussions; VHTs: Village Health Teams; CHC: Communication for Healthy Communities.

\section{Introduction}

There is increasing global concern on early initiation of sexual activity among adolescents, the increasing sexually transmitted infections, and teenage pregnancy (UBOS, 2018; UBOS, 2011; Kaestle, Halpern, Miller, \& Ford, 2005; Brooks-Gunn \& Furstenberg Jr, 1989). Discussing sexual and reproductive health (SRH) issues with key influencing audiences to change adolescent sexual behaviors is pertinent. Sexuality education has featured prominently in the global adolescent health discourse (Asampong, Osafo, Bingenheimer, \& Ahiadeke, 2013; Singh, Bankole, \& Woog, 2005), where discussion of sexuality issues with key influencing audiences was found to be associated with adolescent sexual decision making (Meschke, Bartholomae, \& Zentall, 2002; Somers, Tolia, \& Anagurthi, 2012). In Uganda, alarming adolescent health statistics have been recorded including, 19\% of adolescent girls aged 15-19 have had a live birth, 10\% of girls and 17\% of boys age 15-19 reported to have had sexual intercourse by age 15 , and an HIV prevalence of $6 \%$ with $1.8 \%$ among adolescent girls and $0.4 \%$ among 
boys (UBOS, 2018). In Uganda, little is known about the effects of discussing sexual and reproductive health issues with key influencing audiences on adolescent sexual behaviors. This article explores adolescents' perceptions on adolescence stage, sexual behaviors and sexual behavioral changes associated with adolescent discussion and interactions with key influencing audiences such as parents, peers, health workers, village health teams (community health workers) and religious leaders. Several studies found parent-adolescent communication to be effective in influencing adolescent sexual behaviors such as delayed sexual debut, condom use, reduction of multiple concurrent partnerships, and contraceptive use (Rodgers 1999; Biddlecom, Awusabo-Asare, \& Bankole, 2009; Hadley et al., 2009; Eisenberg, Sieving, Bearinger, Swain, \& Resnick, 2006). However, there are persistent barriers in parent-adolescent communication concerning sex such as embarrassment, lack of knowledge, poorly defined values, fear of encouraging sexual activity, and inability to initiate and maintain a conversation about the subject (Pick \& Palos, 1995; Werner-Wilson \& Fitzharris, 2001). When adolescents do not get sexuality information from parents, they turn to and rely more on their peers for the information (Whitaker \& Miller, 2000; Kioli, 2017). Peer-adolescent communication has been found to influence adolescent sexual behavior (Whitbeck, Conger, \& Kao, 1993). Health workers and community health workers were found to be a major source of sexuality information for adolescents, often seen as role-models and experts in filling adolescent SRH information needs (Jonas, Crutzen, van den Borne, Reddy, 2017; Tilahun, Mengistie, Egata, \& Reda, 2012). There is increasing involvement of religious groups in local debates over sex education (Brewster, Cooksey, Guilkey, \& Rindfuss, 1998), where religious leaders play a vital role of giving religious teachings about sex education. Religious teachings about sexuality that are against premarital sex create the putative impact of religion on sexual behavior (McCree, Wingood, DiClemente, Davies, \& Harrington, 2003; Landor, Simons, Simons, Brody, \& Gibbons, 2011; Kagimu et al., 2013). Individuals who attend religious services frequently receive religious messages against premarital sex and are more likely to develop sexual attitudes and behaviors that are consistent with their religious doctrines (Odimegwu, 2005). Therefore, exploring the perspectives of adolescent interactions with key influencing audiences is imperative for guiding the design of context appropriate adolescent SRH programs. This study draws on qualitative data from Communication for Healthy Communities program on the behavioral perspectives of adolescent interactions with key influencing audiences.

\subsection{Communication for Healthy Communities Program}

Communication for Healthy Communities (CHC) is a five-year program implemented through a June 2013 cooperative agreement between the United States Agency for International Development Uganda and FHI 360 (Family Health International). It aims to increase adoption of healthy behaviors through strengthened targeted social and behavior change communication (SBCC) of six integrated priority areas including; HIV/AIDS, family planning, maternal and child health, nutrition, malaria and tuberculosis (CHC, 2016). Its overarching programming is based on the Socio-Ecological Model that looks beyond individuals to their social context including - interpersonal, institutional, community and policy (Mckee, Manoncourt, Chin, \& Carnegie, 2002; Golden \& Earp, 2012; Langille \& Rodgers, 2010). The social ecological paradigm is rooted in certain core principles concerning the interrelations among environmental conditions, human behavior and well-being. Environmental settings are characterized as having multiple physical, social, and cultural dimensions that can influence a variety of health outcomes (Stokols, 1996). Grounded in the underlying ideologies of the social ecological model, the program implements an integrated SBCC campaign (called OBULAMU?). OBULAMU? or "How is Life?" is an innovative approach to standardize and revitalize health communication in Uganda by putting health in the context of day-to-day life. The campaign premised on a Life Stage approach employs integrated strategies of inter-personal communication by champions such as home visits, community health mobilization events, mass media, social media, print and outdoor media. The integrated strategies trigger dialogue and self-reflection, provide knowledge, motivation and skills on different health areas. The Life Stage approach identifies and addresses evolving health needs over different stages of an individual's life, rather than from a disease focused perspective. The four life stages addressed in the campaign include: 1) Young adults (18-30 years) in relationships; 2) Pregnant women and their male partners; 3) Family with children (0-14 years), targeting caregivers of children under five; and 4) Adolescent girls and boys (15-19 years) (CHC, 2016). The campaign platform uses inter-personal communication as the lead medium, complemented by mass media, social media, print and outdoor media to reach the targeted audiences. When the target audiences are exposed to all types of the campaign interventions, then there is high exposure which is likely to lead to behavior change. The present qualitative study aims to examine the resultant behavioral changes of CHC Life Stage interventions among sexually active adolescents (girls and boys; $15-19$ years) related to condom use, reduction of multiple concurrent partnerships, and contraception use, with specific reference to adolescent interactions with key influencing audiences. 


\section{Methods}

\subsection{Study Methods}

The study used the following methods guided by the consolidated criteria for reporting qualitative research (Tong, Sainsbury, \& Craig, 2007).

\subsubsection{Research Team}

A research team of both male and female data collectors was recruited and trained on qualitative research processes, research ethics, consenting procedures, and on OBULAMU campaign health messaging platform. The data collectors were selected based on demonstrated experience and performance during training and pre-test of data collection tools. The recruited data collectors had knowledge of the local languages used in the selected study sites. This helped in conducting the interviews in the language comfortable for the participants.

\subsubsection{Study Design}

Data for this study was obtained from a non-experimental qualitative study conducted between February to March 2017 in Uganda. Use of the non-experimental qualitative study approach helped to describe, gather an authentic understanding of, and find the reasons for adolescent health behavior and its social context (Marston \& King, 2006; Seale \& Silverman, 1997; Baxter \& Jack, 2008; Creswell, Hanson, Clark-Plano, \& Morales, 2007). The qualitative study used a case study of Communication for Healthy Communities program in Uganda. Qualitative case study methodology provides tools for researchers to study complex phenomena within their contexts (Baxter \& Jack, 2008). The aim of a case study design is not to find out how often something occurs in a population, but rather what occurred, why it occurred, and what relationship exists among observed events. To generate health behavioral change insights from adolescents, the study employed a Most Significant Change methodology. The Most Significant Change methodology is a dialogical, story-based technique often used to generate knowledge on a phenomenon (Davies \& Dart, 2005; Dart \& Davies, 2003).

\subsubsection{Study Setting}

Data was collected in four purposively selected districts of Lira, Mukono, Iganga, and Kyenjojo in Uganda. The sites selection was based on existence of program campaign interventions specifically interpersonal communication and mass media; urban and rural representation to achieve maximum variation in terms of geographical contexts; and existence of adolescent-focused sub-program activities such as the Determined, Resilient, Empowered, AIDS-free, Mentored Safe (DREAMS Core Package of Interventions Summary), the Accelerating the Rise of Contraceptive Prevalence, and the Saving Mothers Giving Life programs (SMGL, 2014).

\subsubsection{Participant Selection}

The study employed purposive sampling strategies particularly snowball and convenience sampling in the recruitment of participants. Using convenience sampling, adolescents were recruited for in-depth interviews (IDIs) through community organizations by working with community and peer champions, and programs that provide SRH services to young girls and boys such as School Health Programs, Straight Talk Foundation, and partners implementing Stepping Stones approach (ACORD, 2007) in selected districts. Convenience sampling is a non-probabilistic sampling procedure that enabled researching subjects of the population that were easily accessible to the data collectors (Etikan, Musa, \& Alkassim, 2016; Farrokhi \& Mahmoudi-Hamidabad, 2012). Focus group discussion (FGD) participants were recruited using snowball sampling from IDI participants. Snowball sampling procedure enabled data collectors to access FGD informants through contact information that was provided by IDI informants (Noy, 2008; Sadler, Lee, Lim, \& Fullerton, 2010). Adolescents who had been exposed to CHC interventions at various levels including mass media, non-home-based activations supported by champions, and champion home visits, were recruited for IDIs and FGDs. The study aimed at recruiting potential sexually active adolescents 15-19 years for both IDIs and FGDs.

\subsubsection{Data Collection Methods}

In-depth interviews and focus group discussions were conducted in sequence. IDIs with adolescents aged 15-19 were conducted first and respondents contacts were taken to be contacted on another date to participate in FGDs. This helped in giving time for snowballing other FGD participants. FGDs were conducted after IDIs with adolescents aged 15-19 and young lovers in relationships aged 18-30 because these target groups overlap and often have similar characteristics related to sexual behaviors. Interview guides for the IDIs and FGDs were developed using program SBCC strategy and objectives for the targeted population group, and they were refined during data collectors' training using trainee pre-test experience and using data from the pre-test exercise. The questions in the interview guides focused on-existence and appropriateness of health services or information 
sources in the community, the environmental (household, community, structural, or health system) factors perceived to affect ability to take up health services and healthy behaviors, health messages that people have been exposed to, the perceived most significant contribution of integrated health communication intervention in their lives and community, and noted health behavior changes. IDIs were conducted to gather detailed information (Boyce \& Neale, 2006) on the effect of discussing selected health topics within the adolescent social networks on individual's intentions and action/behaviors. A total of sixteen IDIs were conducted, eight for males and eight for females. FGDs were conducted to understand how the normative environment and service delivery context in communities potentially interacted with individual's health behaviors, and the role interpersonal communication played to complement health communication. To enable full participation, FGDs were conducted separately with male and female respondents. In total, eight FGDs, four for males and four for females were conducted. Each FGD had between $8-12$ participants.

\subsection{Ethical Approval}

Ethical approval was obtained from the federally-registered institutional review board of FHI 360 (Family Health International), the Protection of Human Subjects Committee in the United States of America, under reference 939934, and in Uganda by the Makerere School of Public Health Research Ethics Committee, under reference 446. Consent to conduct research was provided by Uganda National Council for Science and Technology and Office of the President. Oral informed consent was obtained from each participant before any study specific activities were undertaken. A waiver of written consent to increase confidentiality was sought because signed informed consent forms would be the only link to the participants' identity in the study population groups. A waiver of parental consent was also sought to protect adolescent participants' privacy, particularly around disclosure of sexual behavior, and because recruitment was conducted away from homes in some cases and based on convenience sampling, which is not conducive to parental consent. Once eligibility was established for study participants, full verbal informed consent was obtained from each study participant aged 15-19 before any research activities were undertaken. Verbal informed consent was sought for mature/ emancipated minors aged 15-17 years who were not under parental/ guardian care but catered for their own livelihood. Consent was documented for each participant via signature of the study staff member who obtained consent.

\subsection{Data Analysis}

Audio-recorded data from IDIs and FGDs collected in the local language was translated into English after verbatim transcription. The IDIs lasted an average of 45 minutes (excluding informed consent process), while FGDs lasted an average of $1 \frac{1}{2}$ hours (excluding informed consent process). All interviews were audio recorded to ensure that all data were captured. NVivo 11 software was used to facilitate the data coding process. The software package provided a simple to work with structure for creating codes and discovering themes (Zamawe, 2015; Abuya, Oketch, \& Musyoka, 2013). Analysis codes, such as experience on adolescence stage, sexual behaviors (condom use, contraception use, multiple concurrent partnerships), and effect of key influencing audiences were developed to guide generation of concepts that emerged from the data. Codes were also identified from reading the first set of transcripts. Thematic content analysis was used to organize the data into themes and sub-themes used to develop emerging concepts and interpret meaning of adolescent health behaviors drawn from the study. Thematic content analysis was used to describe the naturalistic phenomenon of adolescent sexual behaviors. The analysis adopted analytic approaches ranging from impressionistic, intuitive, interpretive analyses to systematic and textual analyses (Zamawe, 2015). Thematic content analysis was chosen to help in gaining direct information from study participants without imposing preconceived categories or theoretical perspectives (Hsieh \& Shannon, 2005).

\section{Results}

\subsection{Demographic Characteristics of Respondents}

A total of 83 adolescents participated in the study. Of these, 16 respondents participated in in-depth interviews and 67 respondents participated in focus group discussions. Most of the respondents were female. Regarding education level, most respondents had started secondary school, and many were not married. Most respondents were Protestants and Catholics (Table 1). 
Table 1. Demographic characteristics of Adolescents

\begin{tabular}{|c|c|c|c|c|}
\hline \multirow{2}{*}{\multicolumn{2}{|c|}{ Demographic categories }} & \multicolumn{3}{|c|}{ Frequency and percentage (\%) } \\
\hline & & \multirow{2}{*}{$\begin{array}{l}\text { All adolescents }(N=83) \\
9(11 \%)\end{array}$} & \multirow{2}{*}{$\begin{array}{l}\text { Girls }(N=53) \\
5(9 \%)\end{array}$} & \multirow{2}{*}{$\begin{array}{l}\text { Boys }(N=30) \\
4(13 \%)\end{array}$} \\
\hline \multirow{5}{*}{ Age } & 15 & & & \\
\hline & 16 & $5(6 \%)$ & $3(6 \%)$ & $2(7 \%)$ \\
\hline & 17 & $17(21 \%)$ & $13(25 \%)$ & $4(13 \%)$ \\
\hline & 18 & $18(22 \%)$ & $8(15 \%)$ & $10(33 \%)$ \\
\hline & 19 & $34(41 \%)$ & $24(45 \%)$ & $10(33 \%)$ \\
\hline \multirow{5}{*}{ Education level } & Started primary & $12(15 \%)$ & $8(15 \%)$ & $4(13 \%)$ \\
\hline & Completed primary & $15(18 \%)$ & $10(19 \%)$ & $5(17 \%)$ \\
\hline & Started secondary & $42(51 \%)$ & $29(55 \%)$ & $13(43 \%)$ \\
\hline & Completed secondary & $12(15 \%)$ & $5(9 \%)$ & $7(23 \%)$ \\
\hline & Higher than secondary & $2(2 \%)$ & $1(2 \%)$ & $1(3 \%)$ \\
\hline \multirow{4}{*}{ Relationship status } & Single & $54(65 \%)$ & $30(57 \%)$ & $24(80 \%)$ \\
\hline & Dating & $19(23 \%)$ & $15(28 \%)$ & $4(13 \%)$ \\
\hline & Living with partner, but not married & $1(1 \%)$ & 0 & $1(3 \%)$ \\
\hline & Married & $9(11 \%)$ & $8(15 \%)$ & $1(3 \%)$ \\
\hline \multirow{3}{*}{ Religion } & Catholic & $28(39 \%)$ & $17(37 \%)$ & $11(42 \%)$ \\
\hline & Muslim & $10(14 \%)$ & $5(11 \%)$ & $5(19 \%)$ \\
\hline & Protestant & $34(47 \%)$ & $24(52 \%)$ & $10(39 \%)$ \\
\hline
\end{tabular}

\subsection{Experience of Respondents on Adolescence Stage}

When asked about their experience on adolescence, the respondents mentioned that adolescence stage comes with changes. They noted that the changes are often seen in increasing sexual desires and feelings that may make adolescents sexually active, and yet controlling the sexual desire is a challenge. The respondents further noted that adolescence is associated with a lot of peer influence that sometimes affects adolescents negatively because it leads them to engage in activities that they feel are not good. Others perceived adolescence as a time where youth have fun and face so many temptations (Figure 1).

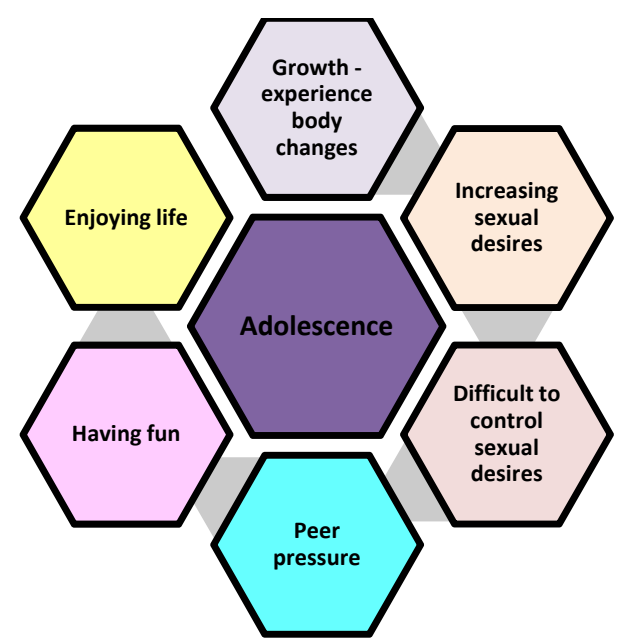

Figure 1. Respondents' experience on adolescence stage 
The change is in growth, like at this moment I am an adolescent, yeah? I have started changing, let's say I am now experiencing my monthly periods. And another change is that I have started getting sexual feelings towards men. (IDI, Female adolescent, Lira district).

Sometimes the sexual desires are intense and therefore, controlling the desires as you are not supposed to get involved in such (sexual) acts is a challenge. (IDI, Female adolescent, Lira district).

I realized that I had many friends who bring peer pressure, and they make us to do things that we should not have done as youths. The adolescent stage disturbs us a lot thus doing things that we shouldn't have done.... (IDI, Male adolescent, Lira district).

Youth of today like having fun and enjoying life and sexual pleasures and they say that the world is coming to an end hence living a reckless life. They don't care to use condom during sex.... (IDI, Female adolescent, Lira district).

\subsection{Adolescent Perceptions on Sexual Behaviors}

Sexual behaviors such as condom use, multiple concurrent partnerships, and contraception were explored in this study. The aim was to understand the perceptions of adolescents on the sexual behaviors including, knowledge, attitudes, myths and misconceptions.

\subsubsection{Perceptions on Condom Use}

Most of the respondents perceived that they had knowledge on condoms and were aware of the benefit of using them. Although some adolescents noted that they did not know how to use condoms, others highlighted that there are complications and side effects associated with using condoms, an indication of existing myths and misconceptions. The participants noted that use of condoms promotes premarital sex, it causes diseases to women, and they affect sexual enjoyment (Figure 2).

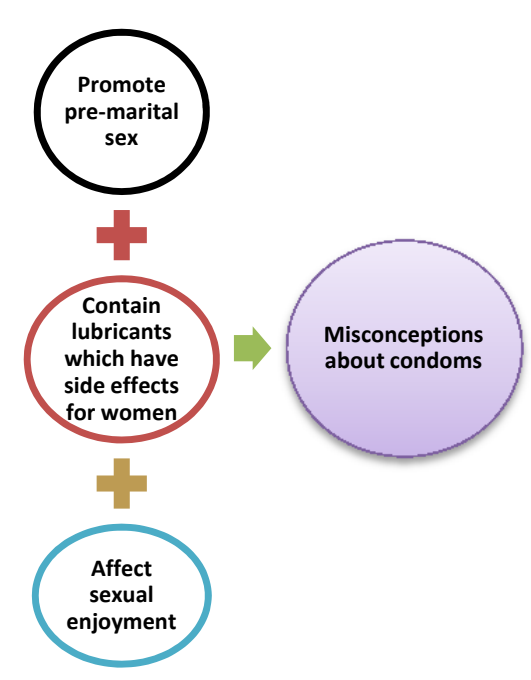

Figure 1. Adolescents' misconceptions

... a condom is a bit different in a way that it plays many roles or more than one function. It prevents us from contracting UTIs, STDs, HIV/AIDS, and even pregnancies... (FGD, Female respondent, Mukono district).

Yes, it is true we are using condoms but they are promoting pre-marital sex. If they tell us to use condoms then also pre-marital sex will increase. (FGD, Male respondent, Iganga district).

These condoms are good but they talk badly about them. They say that when you use condoms, they contain lubricants which have side effects for women after use, and that they may result into complications... (FGD, Female respondent, Mukono district).

When using condom, it's like licking a wrapped sweet, your saliva keeps it soft but you can never taste its sweetness, or it's like eating bananas used for making local brew. You can't feel the taste. (FGD, Male respondent, Kyenjojo district).

\subsubsection{Perceptions on Multiple Concurrent Partnerships}

Most of the respondents noted that they had a history of two or more sexual partners. The participants also stated 
that they knew the importance of being faithful to one partner including, one knows the partner's health, it protects them from diseases, and it brings trust in the relationship. However, others highlighted that faithfulness to one partner is not necessarily easy because youth are not always truthful, and there is usually no trust in the relationship. The respondents also highlight the existence of inter-generational sex, which often times causes gender power imbalance and affects adolescents' ability to negotiate safe sex.

Being with one partner only is good because you will know your health; you are preventing disease and he also trusts you. (FGD, Female adolescent, Lira district).

Faithfulness, that one is hard because you can decide to be faithful to your partner but it is still hard unless when you have got an older man. Getting your age-mate, he can cheat on you with another person and even make you cry. To me that's impossible unless you have got an older man who has settled. (FGD, Female respondent, Mukono district).

Having multiple sexual partners was seen as expensive for boys as they felt that they had to spend a lot of money impressing girls. The respondents highlight the onset of feelings of responsibility with finances among boys. Transactional sex and multiple sexual relationships for money and material gain was mentioned as a factor that makes adolescents girls to have multiple concurrent partnerships.

I would go and give out pocket money of Uganda shillings (UGX) 10,000/- [US\$1 $=U G X 3,696]$ and they would call me a rich man. ...I realized that every day I would spend like 50,000/-...I regretted the money I had spent yet I wanted to buy what to eat but I did not even have 100/- (FGD, Male respondent, Iganga district).

You might find a woman with three men like one is for paying for costs of making her hair, the second is to settle bills for her nail care, and the third is for paying rent. Such a woman may tell her husband to be faithful but the moment the husband leaves she cheats on him. (FGD, Female respondent, Mukono district).

\subsubsection{Perceptions on Contraception Use}

The respondents perceived that they had knowledge on contraception use. Many talked about the benefits of contraception (family planning) as helping to have a number of children one could provide for. The respondents also highlighted the onset of feelings of responsibility to provide partner support in the use of contraception. Some mentioned that they were aware of the possibility of using emergency pills before sex to avoid getting pregnant. Most respondents also cited fears that contraception use has side effects which discourage adolescents from using it. They mentioned side effects such as infertility, swollen wounds and bleeding, making women dry, and loss of sexual appetite presumed to result from using contraception (Figure 3).

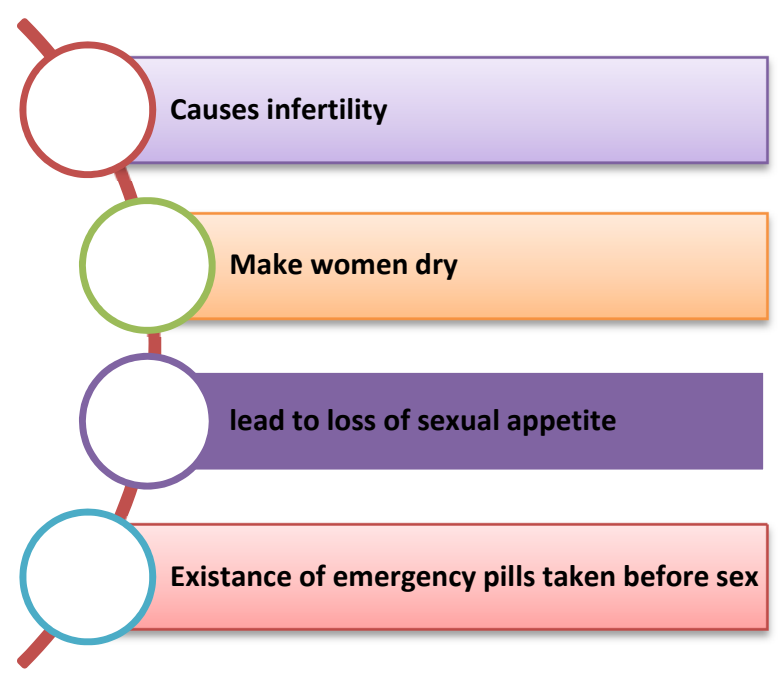

Figure 3. Adolescents' fears about contraception use

The change I have seen is that in the past people used to give birth to many children because there was no family planning, but now people are using family planning. In the near future when I get a wife, I will take her for family planning so that we have two children. This will allow us to take good care of them, feed them well. It will also be easy to take them to good schools. (FGD, Male respondent, Lira district) 
But for my case, I have heard girls saying that, there are certain emergency pills that you take before sex, and you can't get pregnant. (IDI, Female adolescent, Kyenjojo district).

When you talk about using family planning, they do use it, but end up becoming infertile! That's why they fear. (FGD, Female respondent, Kyenjojo district).

These injections have side effects. They make the woman dry, and you lose sexual appetite. (IDI, Female adolescent, Kyenjojo district).

\subsection{The Effect of Key Influencing Audiences on Adolescent Sexual Behaviors}

The respondents were asked if they discuss sexual behaviors such as condom use, multiple concurrent partnerships and contraception use with key influencers such as health workers, VHTs, parents, religious leaders, and peers. Most respondents mentioned that they had discussions with VHTs and peers, and a few with health workers, parents and religious leaders.

\subsubsection{Village Health Teams (VHTs)-Adolescent Interaction and Its Effect on Adolescent Sexual Behavior}

Most adolescents mentioned that they had discussions with VHTs about sexual behaviors. They noted that their interaction with the VHTs had an effect on their behaviors towards behavior change. Some highlighted that using the information they got from VHTs, they gained confidence to start using condoms, contraception, reduce number of sexual partners, and going for HIV testing.

My discussion with the champion (VHT) focused on protection and he was interested in knowing how I go about protecting myself. He talked about family planning in case someone is not abstaining and the use of condoms and IUD. (IDI, Female adolescent, Iganga district).

...he (VHT) just told me that I should leave women and I heeded what he was telling me... The change that I got that was good is that I used to think about girls but now I stopped thinking about them. (IDI, Male adolescent, Iganga district)

Yes, he (VHT) told me about HIV, and I took his advice and went for testing. I did it on 4th October, it was a Tuesday if my memory serves me right. I found that I was negative. (IDI, Male adolescent, Kyenjojo district).

However, the adolescents also highlighted challenges in interacting with VHTs. Some respondents expressed concerns on the nature of meeting they had with the VHTs. They noted that some meetings were held in groups but not necessarily followed up with age-focused or one-on-one discussions to provide a conducive environment for sharing confidential information. Others noted that the age of VHTs made it difficult for them to easily open up during discussions (Figure 4).

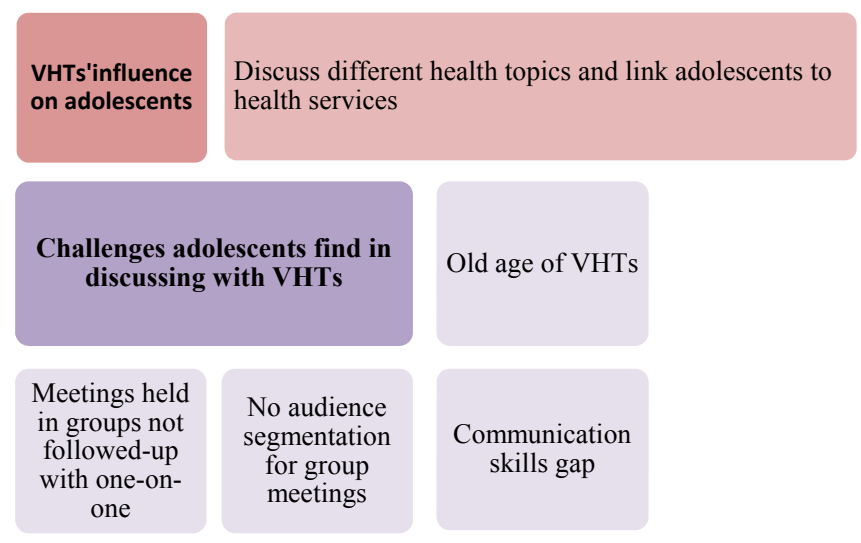

Figure 4. Effect of VHTs discussing with adolescents

In my opinion, he (VHT) had no target because the meeting had individuals aged 65, 19, and 35. The young and old participated; thus, it was general. (IDI, Male adolescent, Mukono district).

We talked to him (VHT) while in a group. It would be very important to talk to him in one-on-one discussions, since I would still need to get more information where I did not understand. (IDI, Male adolescent, Lira district).

What I feel like is an obstacle, is that at times the champions (VHTS) are of my father or mother's age. That is my problem. (IDI, Female adolescent, Lira district). 


\subsubsection{Health Worker-Adolescent Interaction and Its Effect on Adolescent Behavior}

A few adolescents noted that health workers are key in providing information and specific service delivery points that encourages adolescents to take up SRH services such as HIV testing. However, other adolescents had concerns about their interactions with health workers, highlighting that they use a lot of learned (technical) language, and may use harsh or abusive language with clients (Figure 5).

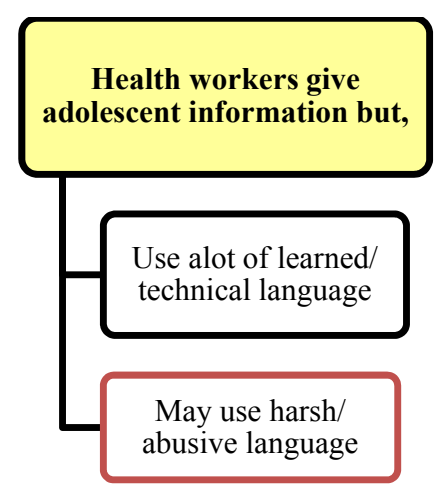

Figure 5. Adolescents' perception on discussing with health workers

Whenever you go to a health facility, the health workers give you a lot of information. For instance, taking an HIV test free of charge and sometimes they have a range of places where we can go to have the tests like at the health facilities. (FGD, Male respondent, Mukono district).

...sometimes the health worker gives me information but as usual, they have a learned language they use, ...so most people (friends) that we usually hang out with know us better than the health workers. (FGD, Male respondent, Mukono district).

For me what I would like to say is that midwives should change their ways. Sometimes you find her inside with the pregnant woman asking her if she is the one who impregnated the patient. She just shouts at you instead of encouraging you. (FGD, Female respondent, Mukono district).

\subsubsection{Parent-Adolescent Interaction and Its Effect on Adolescent Behavior}

A few respondents mentioned having discussions with parents. They noted that they try to get more SRH information from the parents who they see as the first people to guide them, and adolescents pride in trust from parents. However, some adolescents expressed concern of non-availability of parents for SRH discussions because they are too busy and often do not have time for discussion or they try to avoid topics of sexuality (Figure 6).

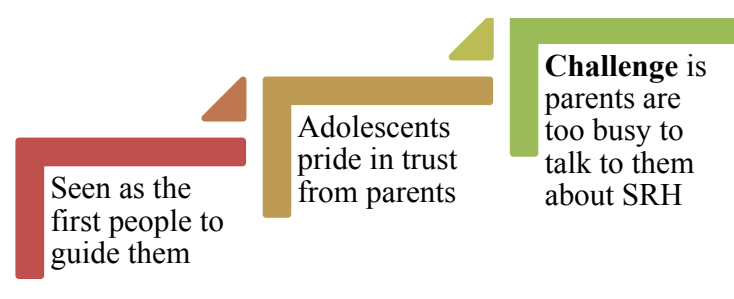

Figure 6. Adolescents' experience interacting with parents

Parents are the first people to guide us; when they see us going astray, and tell us to protect ourselves, and take the right path in life. (IDI, Male adolescent, Kyenjojo district).

When you abstain, your parents trust you, but if you do not, they think their money used for taking you to school is being wasted. (FGD, Female respondent, Kyenjojo district).

The challenge I face is that whenever I ask my mummy about some of these things (sexuality issues), she is too busy to discuss with me. (IDI, Female adolescent, Mukono district). 


\subsubsection{Religious Leaders-Adolescent Interaction and Its Effect on Adolescent Behavior}

A few adolescents talked about interactions with religious leaders, noting that they help in advising the youth to behave well. However, others highlighted that some religions might be discouraging the recommended SRH behaviors such as contraception use.

Religious leaders, they advise the youth; you should behave well, and we should listen to them. (IDI, Male adolescent, Kyenjojo district).

My engagement with church services motivated me. Some of the church members are orphans who have grown up within the church, so I got this opportunity to talk to them. I opened up to them and told them that they are now grown-ups... "So, you must protect yourselves". I guide them about controlling sexual desires even if they are in that age group (adolescents). (IDI, Female respondent, Iganga district).

I am not a Muslim but I usually hear them say that the sharia law does not accept family planning (contraception) use. They say that it will kill their unborn children in the uterus thus limiting the number of children they should have. (FGD, Female adolescent, Iganga district).

\subsubsection{Peer-Adolescent Interaction and Its Effect on Adolescent Behavior}

Most of the respondents mentioned that peers are influential in getting them to take up SRH services. They listen to peer advise and are free to discuss sexuality issues with them. However, others noted that peer groups and pressure can sometimes lead them to engage in bad behavior.

I want to say that close friends or people who we usually hang out with influence us. ... My friend can advise me to take an HIV test by giving an example of his real-life situation.... If your peer features in a health advert, you may decide to follow his advice. (FGD, Male respondent, Mukono district).

We have peer groups like I told you that make us lose focus. They make you to leave something good and you do what is not right thus resulting into problems. (IDI, Male adolescent, Iganga district).

\section{Discussion}

This study explored adolescents' experiences on adolescence stage, perceptions on sexual behaviors, and the effect of interacting and discussing sexual behaviors with key influencers. The findings indicate that adolescence stage comes with changes such as intense sexual desires, which are perceived difficult to control. These findings support other studies which show that adolescence is a critical and vulnerable time of biological, physical, psychological change where youth face new challenges such as initiating sexual activity, entering the age of risk-taking, and entering into unions (Cortez, Saadat, Marinda, \& Odutolu, 2016; Williamson-UNFPA, 2014). With the realities of increasing sexual desires during adolescence, most adolescents indicated that they were aware of sexual behaviors such as condom use, contraception use, and multiple concurrent partnerships. However, Radecki and Jaccard (1995) found that adolescent perceptions of their knowledge about sex and birth control are only weakly correlated with their performance on knowledge tests about these topics, which suggests that perceptions of knowledge are not reflective of the actual knowledge an individual possesses. Thus, adolescent claims of high knowledge levels on health risks should not be trusted (Jaccard, Dodge, \& Dittus, 2002). Our study concurs with these findings where adolescents presumed to have knowledge about health risks. However, what they called knowledge was actually laced with a lot of hearsay, myths, and misconceptions. This implies that health promotion practitioners still need to increase adolescents' knowledge on these SRH topics. Therefore, information services remain important in clearing any misconceptions and addressing any health concerns for increased service uptake.

Most adolescents in this study highlighted that discussing SRH issues with someone was fundamental in influencing their sexual behaviors. Several studies indicate that parent-adolescent interaction and communication was found to be associated with reduced sexual risk taking on the part of adolescents (Asampong et al.,2013; Dittus \& Jaccard, 2000; Jaccard et al., 2002). The function of parents is to motivate and guide the behavior of their children (Jaccard et al., 2002). Whitaker and Miller (2000) found that peer norms were associated more strongly with behavior for those adolescents who had not discussed sex or condoms with a parent than for those who had engaged in such discussions. The non-initiation of sex was found to be associated with adolescents believing parents care and hold high expectations for their children (Asampong et al., 2013). Consistent with other studies, our findings indicate that adolescents see parents as the first people to give them guidance, and adolescents pride in being trusted by their parents. However, adolescents in our study indicated challenges that hinder parent-adolescent discussion such as parents being too busy and not having time to talk to their children. Similar findings were reported in a study by Löfgren, Byamugisha, Tillgren \& Rubenson (2009), in which parents' lack of time to talk to their children was noted to hinder parent-adolescent communication. Additionally, our findings 
concur with other studies which found that parents often have difficulty finding the right place and time for communication because they feel inadequately informed, embarrassed and uncomfortable discussing sexuality topics (Feldman \& Rosenthal, 2000; Jaccard et al., 2002; Taffa, Haimanot, Desalegn, Tesfaye, \& Mohammed, 2017; Bastien et al., 2011). Other studies recommend that a comprehensive family life education should be initiated at home, in the school, churches/mosques, and health facilities, with a sense of responsibility assumed by all partners; and there is need to educate parents for a better awareness on sexuality and change of attitude and practice towards adolescent sexuality (Taffa et al., 2017; Bastien, Kajula, \& Muhwezi, 2011; Löfgren et al., 2009). Our findings seem to suggest the need to sensitize parents about making time to talk to their children about sexuality before sexual debut. It is also imperative to strengthen parents' communication skills about SRH to boost their confidence in talking about sexuality issues with adolescents.

Religious leaders were highlighted by adolescents in this study as being instrumental in motivating and advising the youth to behave well. This finding corroborates other studies which found that adolescents who reported not engaging in sexual intercourse cited religious or moral values as their motivation for abstinence from sexual activity (Odimegwu, 2005; Rostosky, Wilcox, Wright, \& Randall, 2004). However, our study also found that adolescents felt that some religious affiliations were discouraging the use of contraception. This is consistent with other studies that reported significant correlations between more conservative religious affiliations and a lack of contraceptive use among adolescent girls (Brewster et al., 1998; Cooksey, Rindfuss, \& Guilkey, 1996; Rostosky et al., 2004). Similarly, Lefkowitz, Gillen, Shearer, \& Boone, (2004) found that individuals who followed their religions more closely were less likely to believe that condoms could prevent negative outcomes such as pregnancy or sexually transmitted diseases. And individuals who attended religious services more frequently had less fear about HIV (Lefkowitz et al., 2004). Our findings suggest the need for health promotion programs to work closely with religious institutions in providing SRH information that addresses myths and misconceptions, foremost being learning from the experiences of existing adolescent health programs which have sensitized religious leaders on SRH issues. There is need for further research to understand how religious leaders' SRH sensitization interventions lead to change in conservative religious doctrines that inhibit contraception and condom use.

Most adolescents in our study mentioned that they had discussions with village health teams (VHTs) about sexual behaviors such as condom use, contraception use and multiple concurrent partnerships. They highlighted that VHTs gave them detailed information which helped them in taking up health services. This supports other studies which found that community health workers can translate health and system information into the community's language, they can successfully teach concepts of primary or secondary prevention and improve access to prenatal care, and they can facilitate community participation in the health system (Witmer, Seifer, Finocchio, Leslie, \& O'neil, 1995; Denno, Hoopes, \& Chandra-Mouli, 2015; Liu, Sullivan, Khan, Sachs, \& Singh, 2011). Our findings suggest that interpersonal communication is highly effective in complementing and clarifying generic messages relayed through mass media (radio, TV, posters). Thus, an indication that a combination of channels in health communication programming is paramount in message saturation, rather than use of one channel. However, adolescents in our study expressed concerns about VHTs being too old to address their information needs, the communication skills of the VHTs, and meetings held in groups not followed up with age-focused or one-on-one discussions. These findings suggest the utmost importance for health promotion programs to address these concerns if adolescent health is to be improved. Such concerns can be addressed through recruiting and training age appropriate peer champions to work with adolescents, providing more resources for supportive supervision to facilitate VHTs' follow-up visits to adolescents met in groups and one-on-one discussions, if group meetings are to be held, age categorization and audience segmentation for the participants ought to be emphasized. This is consistent with other studies which recommended that, health authorities should lead efforts to define and endorse community health workers' roles, while providing strategies for training, supervision, remuneration, recognition, career progression and quality assurance (Mwai et al., 2013), and evaluation programs should be cognizant of the fact that community health worker programs grow and evolve in phases of continuous learning, improvement, and expansion of coverage (Liu et al., 2011). Therefore, drawing experiences from successfully piloted community health workers interventions is pertinent in improving health promotion programming.

Health workers were also identified as an important group that helps adolescents with health issues including giving them health information. However, the adolescents highlighted that sometimes they do not go to health workers because of their attitude, use of technical language and giving unclear information. These findings corroborate other studies that reported negative health workers' attitudes and inadequate skills to communicate to adolescents as barriers for service uptake by adolescents (Jonas et al., 2017; Chaibva, Ehlers, \& Roos, 2010; Chandra-Mouli et al., 2017; Jonas et al., 2018). Therefore, continuous medical education as a method of keeping 
abreast with current and updated knowledge for healthcare workers needs to be addressed, with specific reference on skills of handling adolescents. Adapting the use of successful piloted interventions in addressing myths and misconceptions such as the use of values clarification component under CHC program (CHC, 2016) is pertinent.

Adolescents in our study also highlighted that they find it convenient to discuss health issues with their peers, who often influence them both positively and sometimes negatively in health service uptake. This finding is consistent with other studies which found that friends play an important role in both harmful and positive activities of adolescents (Maxwell, 2002; Brendt, 1999). Adolescents' perceptions that their friends hold sexually liberal attitudes and are sexually active also influence their sexual choices (Whitbeck et al., 1993). Varga (2003) also found that adolescent relationships appear to be driven by pressure from peers and partners to engage in early and unprotected sex as markers of trust or commitment. Our findings indicate that providing adequate SRH information to adolescents should be a priori for guiding peer-adolescent discussions. Monitoring guided peer-adolescent discussions would be the first step in identifying knowledge gaps. This can be done through drawing lessons from existing adolescent health programs that work with adolescent groups and networks using methodologies such as stepping stones (ACORD, 2007) to assess how peer discussions are moderated, and identify areas for improvement.

This study confirms the reality of sexual desires that drive adolescents to engage in sexual activities often with multiple concurrent partners. This contributes to the alarming adolescent SRH indicators of early sexual debut, increasing HIV prevalence, and teenage pregnancies in Uganda. The findings seem to suggest that for improved adolescent health and behavioral outcomes, health promotion programs need to invest in developing the communication skills and bridging the SRH information gaps of key influencing audiences such as community health workers, health workers, parents, religious leaders and peers. Additionally, continued provision of updated $\mathrm{SRH}$ information to adolescents and the general public is important to bridge knowledge gaps. However, it is important to understand the unique information needs of the different audiences and subgroups for targeted programming. Therefore, continuous studies need to be done to understand the different and emerging information needs of adolescents and their key influencers.

\subsection{Study Limitations}

This study had some methodological limitations that need to be considered. The study was conducted in only four districts of Uganda with a few sampled participants, thus this could affect generalizability of the findings. The study also used convenience sampling to recruit participants, but its limitation is that groups chosen by convenience sampling are conducive to self-selection, administrative decision, time of the class, number of the years of exposure and many other polluting influences (Farrokhi \& Mahmoudi-Hamidabad, 2012).

\section{Conclusion}

Adolescent health has been placed on the global agenda where health promotion development practitioners are challenged with finding solutions towards addressing adolescent health problems. Listening to the voice of adolescents themselves provides the first opportunity to understand the contextual problems and thereby work with them to find practicable solutions. The need to integrate community and adolescent social network approaches to work synonymously with health communication interventions is imperative for adolescent health programming.

\section{Authors' Contributions}

$\mathrm{JN}$ led the conceptualization and writing of the manuscript, led data analysis, contributed to study design and data collection; RC, BvdB and PB contributed to conceptualization of this study, data analysis, guided the structuring and technical writing of the manuscript; LB, RB, AZ, RL and GT contributed to study design, supported in data collection and cleaning, and reviewing of the manuscript for consistency. JA contributed to conceptualization of this study, data analysis, guided the structuring and technical writing of the manuscript. All authors reviewed and approved the final version of the manuscript.

\section{Acknowledgements}

The authors wish to thank USAID Uganda for funding the research activities through FHI 360 (Family Health International), and FHI 360 Uganda for approving the use of project (Communication for Healthy Communities) data for this study. The authors thank Maastricht University for funding the present study requirements. The authors thank Daniela Garcia Grandon, Alexis Hoyt, Miriam Nabukenya, and Peter Byansi for supporting data management processes including, cleaning, coding and initial analytical review. The authors also thank Peter Byansi and $\mathrm{CHC}$ regional teams for supporting the field data collection exercise. 


\section{Competing Interests Statement}

The authors declare that there are no competing interests.

\section{References}

Abuya, B., Oketch, M., \& Musyoka, P. (2013). Why do pupils dropout when education is 'free'? Explaining school dropout among the urban poor in Nairobi. Compare: A Journal of Comparative and International Education, 43(6), 740- 762. https://doi.org/10.1080/03057925.2012.707458

ACORD. (2007). IMPLEMENTING STEPPING STONES: A Practical and Strategic Guide for Implementers, Planners and Policy Makers. Retrieved from https://www.k4health.org/sites/default/files/Implementing Stepping Stones.pdf

Asampong, E., Osafo, J., Bingenheimer, J. B., \& Ahiadeke, C. (2013). Adolescents and parents' perceptions of best time for sex and sexual communications from two communities in the Eastern and Volta Regions of Ghana: implications for HIV and AIDS education. BMC International Health and Human Rights, $13(1), 40$. https://doi.org/10.1186/1472-698X-13-40

Bastien, S., Kajula, L. J., \& Muhwezi, W. W. (2011). A review of studies of parent-child communication about sexuality and HIV/AIDS in sub-Saharan Africa. Reproductive Health, 8(1), 25. https://doi.org/10.1186/1742-4755-8-25

Baxter, P., \& Jack, S. (2008). Qualitative case study methodology: Study design and implementation for novice researchers. The qualitative report, 13(4), 544-559.

Biddlecom, A., Awusabo-Asare, K., \& Bankole, A. (2009). Role of parents in adolescent sexual activity and contraceptive use in four African countries. International Perspectives on Sexual and Reproductive Health, 72-81. https://doi.org/10.1363/3507209

Boyce, C., \& Neale, P. (2006). Conducting in-depth interviews: A guide for designing and conducting in-depth interviews for evaluation input. Pathfinder International Tool Series, Monitoring and Evaluation - 2.

Brewster, K. L., Cooksey, E. C., Guilkey, D. K., \& Rindfuss, R. R. (1998). The changing impact of religion on the sexual and contraceptive behavior of adolescent women in the United States. Journal of Marriage and the Family, 493- 504. https://doi.org/10.2307/353864

Brooks-Gunn, J., \& Furstenberg Jr, F. F. (1989). Adolescent sexual behavior. American Psychologist, $44(2), 249$. https://doi.org/10.1037/0003-066X.44.2.249

Chaibva, C. N., Ehlers, V. J., \& Roos, J. H. (2010). Midwives' perceptions about adolescents' utilisation of public prenatal services in Bulawayo, Zimbabwe. Midwifery, 26(6), e16-e20. https://doi.org/10.1016/j.midw.2009.01.001

Chandra-Mouli, V., Parameshwar, P. S., Parry, M., Lane, C., Hainsworth, G., Wong, S., ... \& Say, L. (2017). A never-before opportunity to strengthen investment and action on adolescent contraception, and what we must do to make full use of it. Reproductive Health, 14(1), 85. https://doi.org/10.1186/s12978-017-0347-9

CHC-Communication for Healthy Communities. (2016). OBULAMU National Integrated Health Communication Platform. June 2013 - June 2018.

Cooksey, E. C., Rindfuss, R. R., \& Guilkey, D. K. (1996). The initiation of adolescent sexual and contraceptive behavior during changing times. Journal of Health and Social Behavior, 59-74. https://doi.org/10.2307/2137231

Cortez, R., Saadat, S., Marinda, E., \& Odutolu, O. (2016). Adolescent Fertility and Sexual Health in Nigeria.

Creswell, J. W., Hanson, W. E., Clark Plano, V. L., \& Morales, A. (2007). Qualitative research designs: Selection and implementation. The counselling psychologist, $236-264$. https://doi.org/10.1177/0011000006287390

Dart, J., \& Davies, R. (2003). A dialogical, story-based evaluation tool: The most significant change technique. American Journal of Evaluation, 24(2), 137-155. https://doi.org/10.1177/109821400302400202

Davies, R., \& Dart, J. (2005). The 'most significant change'(MSC) technique. A guide to its use.

Denno, D. M., Hoopes, A. J., \& Chandra-Mouli, V. (2015). Effective strategies to provide adolescent sexual and reproductive health services and to increase demand and community support. Journal of Adolescent Health, 56(1), S22-S41. https://doi.org/10.1016/j.jadohealth.2014.09.012 
Dittus, P. J., \& Jaccard, J. (2000). Adolescents' perceptions of maternal disapproval of sex: relationship to sexual outcomes1. Journal of Adolescent Health, 26(4), 268-278. https://doi.org/10.1016/S1054-139X(99)00096-8

DREAMS Core Package of Interventions Summary. Retrieved from https://www.pepfar.gov/documents/organization/269309.pdf

Eisenberg, M. E., Sieving, R. E., Bearinger, L. H., Swain, C., \& Resnick, M. D. (2006). Parents' communication with adolescents about sexual behavior: A missed opportunity for prevention?. Journal of Youth and Adolescence, 35(6), 893-902. https://doi.org/10.1007/s10964-006-9093-y

Etikan, I., Musa, S. A., \& Alkassim, R. S. (2016). Comparison of convenience sampling and purposive sampling. American Journal of Theoretical and Applied Statistics, 5(1), 1-4. https://doi.org/10.11648/j.ajtas.20160501.11

Farrokhi, F., \& Mahmoudi-Hamidabad, A. (2012). Rethinking convenience sampling: Defining quality criteria. Theory and practice in language studies, 2(4), 784. https://doi.org/10.4304/tpls.2.4.784-792

Feldman, S. S., \& A. Rosenthal, D. (2000). The effect of communication characteristics on family members' perceptions of parents as sex educators. Journal of Research on Adolescence, 10(2), 119-150. https://doi.org/10.1207/SJRA1002_1

Golden, S. D., \& Earp, J. A. L. (2012). Social ecological approaches to individuals and their contexts: twenty years of health education \& behavior health promotion interventions. Health Education \& Behavior, 39(3), 364-372. https://doi.org/10.1177/1090198111418634

Hadley, W., Brown, L. K., Lescano, C. M., Kell, H., Spalding, K., DiClemente, R., ... \& Project STYLE Study Group. (2009). Parent-adolescent sexual communication: Associations of condom use with condom discussions. AIDS and Behavior, 13(5), 997-1004. https://doi.org/10.1007/s10461-008-9468-z

Hsieh, H. F., \& Shannon, S. E. (2005). Three approaches to qualitative content analysis. Qualitative Health Research, 15(9), 1277-1288. https://doi.org/10.1177/1049732305276687

Jaccard, J., Dodge, T., \& Dittus, P. (2002). Parent - adolescent communication about sex and birth control: A conceptual framework. New Directions for Child and Adolescent Development, 2002(97), 9-42. https://doi.org/10.1002/cd.48

Jonas K, Crutzen R, van den Borne B, Reddy P. (2017). Healthcare workers' behaviors and personal determinants associated with providing adequate sexual and reproductive healthcare services in sub-Saharan Africa: A systematic review. BMC Pregnancy and Childbirth, 17(1), 86. https://doi.org/10.1186/s12884-017-1268-x

Jonas, K., Crutzen, R., Krumeich, A., Roman, N., van den Borne, B., \& Reddy, P. (2018). Healthcare workers' beliefs, motivations and behaviours affecting adequate provision of sexual and reproductive healthcare services to adolescents in Cape Town, South Africa: A qualitative study. BMC Health Services Research, 18(1), 109. https://doi.org/10.1186/s12913-018-2917-0

Kaestle, C. E., Halpern, C. T., Miller, W. C., \& Ford, C. A. (2005). Young age at first sexual intercourse and sexually transmitted infections in adolescents and young adults. American Journal of Epidemiology, 161(8), 774-780. https://doi.org/10.1093/aje/kwi095

Kagimu, M., Guwatudde, D., Rwabukwali, C., Kaye, S., Walakira, Y., \& Ainomugisha, D. (2013). Religiosity for promotion of behaviors likely to reduce new HIV infections in Uganda: A study among Muslim youth in Wakiso district. Journal of Religion and Health, 52(4), 1211-1227. https://doi.org/10.1007/s10943-011-9563-8

Kioli, F. N. (2017). An investigation into the socio-cultural and economic factors that influence pre-marital sexual behavior among adolescents: the case of Makadara division, Nairobi (Doctoral dissertation).

Landor, A., Simons, L. G., Simons, R. L., Brody, G. H., \& Gibbons, F. X. (2011). The role of religiosity in the relationship between parents, peers, and adolescent risky sexual behavior. Journal of Youth and Adolescence, 40(3), 296-309. https://doi.org/10.1007/s10964-010-9598-2

Langille, J. L. D., \& Rodgers, W. M. (2010). Exploring the influence of a social ecological model on school-based physical activity. Health Education \& Behavior, 37(6), 879-894. https://doi.org/10.1177/1090198110367877

Lefkowitz, E. S., Gillen, M. M., Shearer, C. L., \& Boone, T. L. (2004). Religiosity, sexual behaviors, and sexual attitudes during emerging adulthood. Journal of Sex Research, 41(2), 150-159. https://doi.org/10.1080/00224490409552223 
Liu, A., Sullivan, S., Khan, M., Sachs, S., \& Singh, P. (2011). Community health workers in global health: scale and scalability. Mount Sinai Journal of Medicine: A Journal of Translational and Personalized Medicine, 78(3), 419- 435. https://doi.org/10.1002/msj.20260

Löfgren, J., Byamugisha, J., Tillgren, P., \& Rubenson, B. (2009). The perspectives of in-school youths in Kampala, Uganda, on the role of parents in HIV prevention. African Journal of AIDS Research, 8(2), 193-200. https://doi.org/10.2989/AJAR.2009.8.2.7.859

Marston, C., \& King, E. (2006). Factors that shape young people's sexual behaviour: a systematic review. The Lancet, 368(9547), 1581-1586. https://doi.org/10.1016/S0140-6736(06)69662-1

Maxwell, K. A. (2002). Friends: The role of peer influence across adolescent risk behaviors. Journal of Youth and Adolescence, 31(4), 267-277. https://doi.org/10.1023/A:1015493316865

McCree, D. H., Wingood, G. M., DiClemente, R., Davies, S., \& Harrington, K. F. (2003). Religiosity and risky sexual behavior in African-American adolescent females. Journal of Adolescent Health, 33(1), 2-8. https://doi.org/10.1016/S1054-139X(02)00460-3

Mckee, N., Manoncourt, E., Chin, S.Y. \& Carnegie, R. (2002). Chapter 12. Involving People, Evolving Behaviour: The UNICEF experience. In: SERVAES, J. (ed.), Approaches to Development Communication. Paris: UNESCO.

Meschke, L. L., Bartholomae, S., \& Zentall, S. R. (2002). Adolescent sexuality and parent-adolescent processes: Promoting healthy teen choices. Journal of Adolescent Health, 31(6), 264-279. https://doi.org/10.1016/S1054-139X(02)00499-8

Mwai, G. W., Mburu, G., Torpey, K., Frost, P., Ford, N., \& Seeley, J. (2013). Role and outcomes of community health workers in HIV care in sub - Saharan Africa: A systematic review. Journal of the International AIDS Society, 16(1). https://doi.org/10.7448/IAS.16.1.18586

Noy, C. (2008). Sampling knowledge: The hermeneutics of snowball sampling in qualitative research. International Journal of Social Research Methodology, 11(4), $327-344$. https://doi.org/10.1080/13645570701401305

Odimegwu, C. (2005). Influence of religion on adolescent sexual attitudes and behaviour among Nigerian university students: Affiliation or commitment? African Journal of Reproductive Health, 125-140. https://doi.org/10.2307/3583469

Pick, S., \& Palos, P. A. (1995). Impact of the family on the sex lives of adolescents. Adolescence, 30(119), 667.

Radecki, C. M., \& Jaccard, J. (1995). Perceptions of knowledge, actual knowledge, and information search behavior. Journal of Experimental Social Psychology, 31(2), 107-138. https://doi.org/10.1006/jesp.1995.1006

Rodgers, K. B. (1999). Parenting processes related to sexual risk-taking behaviors of adolescent males and females. Journal of Marriage and the Family, 99-109. https://doi.org/10.2307/353886

Rostosky, S. S., Wilcox, B. L., Wright, M. L. C., \& Randall, B. A. (2004). The impact of religiosity on adolescent sexual behavior: A review of the evidence. Journal of Adolescent Research, 19(6), 677-697. https://doi.org/10.1177/0743558403260019

Sadler, G. R., Lee, H. C., Lim, R. S. H., \& Fullerton, J. (2010). Recruitment of hard - to - reach population subgroups via adaptations of the snowball sampling strategy. Nursing \& Health Sciences, 12(3), 369-374. https://doi.org/10.1111/j.1442-2018.2010.00541.x

Seale, C., \& Silverman, D. (1997). Ensuring rigour in qualitative research. The European Journal of Public Health, 7(4), 379-384. https://doi.org/10.1093/eurpub/7.4.379

Singh, S., Bankole, A., \& Woog, V. (2005). Evaluating the need for sex education in developing countries: sexual behaviour, knowledge of preventing sexually transmitted infections/HIV and unplanned pregnancy. Sex education, 5(4), 307-331. https://doi.org/10.1080/14681810500278089

SMGL. (2014). Saving Mothers Giving Life-Uganda. Retrieved from https://www.savingmothersgivinglife.org/docs/SMGL_Uganda_Backgrounder.pdf

Somers, C. L., Tolia, S., \& Anagurthi, C. (2012). Parent-Adolescent relationships and adolescent sexual behavior: Patterns by adolescent gender. International Journal of Business and Social Science, 3(7).

Stokols, D. (1996). Translating social ecological theory into guidelines for community health promotion. 
American Journal of Health Promotion, 10(4), 282-298. https://doi.org/10.4278/0890-1171-10.4.282

Taffa, N., Haimanot, R., Desalegn, S., Tesfaye, A., \& Mohammed, K. (2017). Do parents and young people communicate on sexual matters. The Ethiopian Journal of Health Development (EJHD), 13(3).

Tilahun, M., Mengistie, B., Egata, G., \& Reda, A. A. (2012). Health workers' attitudes toward sexual and reproductive health services for unmarried adolescents in Ethiopia. Reproductive Health, 9(1), 19. https://doi.org/10.1186/1742-4755-9-19

Tong, A., Sainsbury, P., \& Craig, J. (2007). Consolidated criteria for reporting qualitative research (COREQ): A 32-item checklist for interviews and focus groups. International Journal for Quality in Health Care, 19(6), 349-357. https://doi.org/10.1093/intqhe/mzm042

Uganda Bureau of Statistics (UBOS) and ICF. (2012). Uganda Demographic and Health Survey 2011. Kampala, Uganda: UBOS and Calverton, Maryland: ICF International Inc.

Uganda Bureau of Statistics (UBOS) and ICF. (2018). Uganda Demographic and Health Survey 2016. Kampala, Uganda and Rockville, Maryland, USA: UBOS and ICF.

Varga, C. A. (2003). How gender roles influence sexual and reproductive health among South African adolescents. Studies in Family Planning, 34(3), 160-172. https://doi.org/10.1111/j.1728-4465.2003.00160.x

Werner-Wilson, R. J., \& Fitzharris, J. L. (2001). How can mothers and fathers become involved in the sexuality education of adolescents? Journal of HIV/AIDS Prevention \& Education for Adolescents \& Children, 4(1), 49-59. https://doi.org/10.1300/J129v04n01_05

Whitaker, D. J., \& Miller, K. S. (2000). Parent-adolescent discussions about sex and condoms: Impact on peer influences of sexual risk behavior. Journal of Adolescent research, 15(2), 251-273. https://doi.org/10.1177/0743558400152004

Whitbeck, L. B., Conger, R. D., \& Kao, M. Y. (1993). The influence of parental support, depressed affect, and peers on the sexual behaviors of adolescent girls. Journal of Family Issues, 14(2), 261-278. https://doi.org/10.1177/019251393014002006

Williamson, N. - UNFPA (2014). State of the World Population 2013. Motherhood in Childhood: Facing the Challenge of Adolescent Pregnancy. New York: United Nations Population Fund.

Witmer, A., Seifer, S. D., Finocchio, L., Leslie, J., \& O'neil, E. H. (1995). Community health workers: integral members of the health care work force. American Journal of Public Health, 85(8_Pt_1), 1055-1058. https://doi.org/10.2105/AJPH.85.8_Pt_1.1055

Zamawe, F. C. (2015). The implication of using NVivo software in qualitative data analysis: Evidence-based reflections. Malawi Medical Journal, 27(1), 13-15. https://doi.org/10.4314/mmj.v27i1.4

\section{Copyrights}

Copyright for this article is retained by the author(s), with first publication rights granted to the journal.

This is an open-access article distributed under the terms and conditions of the Creative Commons Attribution license (http://creativecommons.org/licenses/by/4.0/). 